\title{
Two cases of retroperitoneal haematoma caused by interaction between antibiotics and warfarin
}

\author{
S Phillips, A Barr, E Wilson, T A Rockall, J F Stebbing
}

Emerg Med J 2006;23:e8 (http://www.emjonline.com/cgi/content/full/23/1/e8). doi: 10.1136/emj.2004.016345

Several commonly prescribed antibiotics are known to interact with warfarin, increasing its anticoagulant effect by different mechanisms. Retroperitoneal bleeding with consequent haematoma is recognised as a complication of overanticoagulation. Consequences, which are potentially fatal, include hypovolaemic shock and compression of retroperitoneal structures such as the ureter and inferior vena cava.

$\mathrm{S}$ everal commonly prescribed antibiotics are known to interact with warfarin, increasing its anticoagulant effect by different mechanisms. Retroperitoneal bleeding and consequent haematoma are well known complications of over-anticoagulation. We describe two patients in which this complication arose.

\section{PATIENT 1}

A 60 year old woman presented with a 3 day history of right sided abdominal pain. The patient had been started on warfarin 4 weeks previously, after diagnosis of pulmonary embolism (PE). The level of anticoagulation had been stable for the previous 2 weeks. Five days prior to admission the patient had developed a symptomatic urinary tract infection and was treated with trimethoprim, cephalexin, and metronidazole. Other medication comprised nifedipine, acebutolol, and indapamide. Examination revealed a tender mass in the right lower abdomen. Her haemoglobin level was $135 \mathrm{~g} / \mathrm{l}$ and international normalised ratio (INR) was 4.7. Computerised tomography (CT) scan showed a rectus sheath haematoma. Warfarin and antibiotics were stopped and she was admitted for observation and analgesia.

On the third day of admission, the patient became acutely unwell, with signs of hypovolaemic shock. Her haemoglobin level dropped to $47 \mathrm{~g} / \mathrm{l}$ and INR increased to 8.5. The clotting abnormality was treated with $10 \mathrm{mg}$ vitamin $\mathrm{K}$ intravenously and an intravenous infusion of $15 \mathrm{ml} / \mathrm{kg}$ fresh frozen plasma. Transfusion of 6 units of blood was given to treat the hypovolaemia. On the following day, her haemoglobin level had risen to $104 \mathrm{~g} / \mathrm{l}$ and INR corrected to 1.2. CT showed a rectus sheath haematoma and a large retroperitoneal haematoma (fig 1A). Two days later, she developed a painful, swollen right leg and ultrasound scan confirmed a deep vein thrombosis in the femoral vein. Proactive management with an inferior vena cava (IVC) filter was initiated to avoid the need for further anticoagulation. Several days later, the patient developed worsening pain, persistent pyrexia, and elevated white cell count. The haematoma was reassessed with a further CT scan, which revealed compression of the right ureter. Concerns that the obstructed right kidney and/or the haematoma could be infected prompted placement of a ureteric stent to relieve the obstruction and a percutaneous drain to evacuate the haematoma. Following placement of the IVC filter, ureteric stent and drain, the patient's recovery was then uneventful.

\section{PATIENT 2}

A 69 year old woman presented with a 2 day history of right flank pain, which had been precipitated by an episode of coughing. She had been taking warfarin for 9 years since paroxysmal atrial fibrillation was diagnosed when she suffered three transient ischaemic attacks. For several months, the patient had been taking $2 \mathrm{mg}$ daily and the INR had consistently been between 2.0 and 3.0. One week prior to admission the patient had been prescribed a course of clarithromycin (Klaricid; Abbott Laboratories Ltd, Maidenhead, Berkshire, UK) for a chest infection. Other regular medication included perindopril, loperamide, monthly vitamin B12 injections, folic acid, quinine, Combivent inhaler (Boehringer Ingelheim Ltd, Ellesfield Ave, Bracknell, Berkshire, UK), and Seretide inhaler (Glaxo Smith Kline, Stockley Park West, Uxbridge, Middlesex, UK), all of which she had been taking for at least 1 year.

Examination revealed right sided abdominal tenderness. Haemoglobin level was $133 \mathrm{~g} / \mathrm{l}$ and INR was 7.1. CT demonstrated a large retroperitoneal haematoma (fig 1B). She was admitted for observation and analgesia, and was treated with $2 \mathrm{mg}$ vitamin K intravenously. On the next day, INR was 1.1 and haemoglobin level had dropped to $104 \mathrm{~g} / \mathrm{l}$. Transfusion of 2 units of blood was given. All symptoms resolved over the next week and she was discharged home on aspirin and clopidogrel (Plavix; Bristol-Myers Squibb Pharmaceuticals Ltd, Hounslow, Middlesex, UK and SanofiSynthelabo, Guildford, Surrey, UK, respectively) instead of warfarin.

\section{DISCUSSION}

Warfarin is a 4-hydroxycoumarin compound, which exerts an anticoagulant effect by interfering with the vitamin $\mathrm{K}$ dependent $\gamma$-carboxylation of glutamate residues at the amino terminus of coagulation factors II (prothrombin), VII, IX, and X. Partially carboxylated and decarboxylated proteins have a lower level of activity in the coagulation cascade than carboxylated factors. ${ }^{1}$ A wide range of medications, including some antibiotics, potentiates the anticoagulant action of warfarin. ${ }^{1}$ Our first patient had been treated for a urinary tract infection with trimethoprim, cephalexin, and metronidazole. The second patient had been prescribed clarithromycin, a macrolide antibiotic, for a lower respiratory tract infection. In both cases the INR had been stable within the recommended therapeutic range ${ }^{2}$ prior to treatment with antibiotics. Trimethoprim and metronidazole prolong the prothrombin time by inhibition of the clearance of warfarin. ${ }^{1}$ The mechanism by which macrolides prolong the prothrombin time is unknown. ${ }^{1}$

Abbreviations: $\mathrm{CT}$, computed tomography; INR, international normalised ratio; IVC, inferior vena cava; PE, pulmonary embolism 

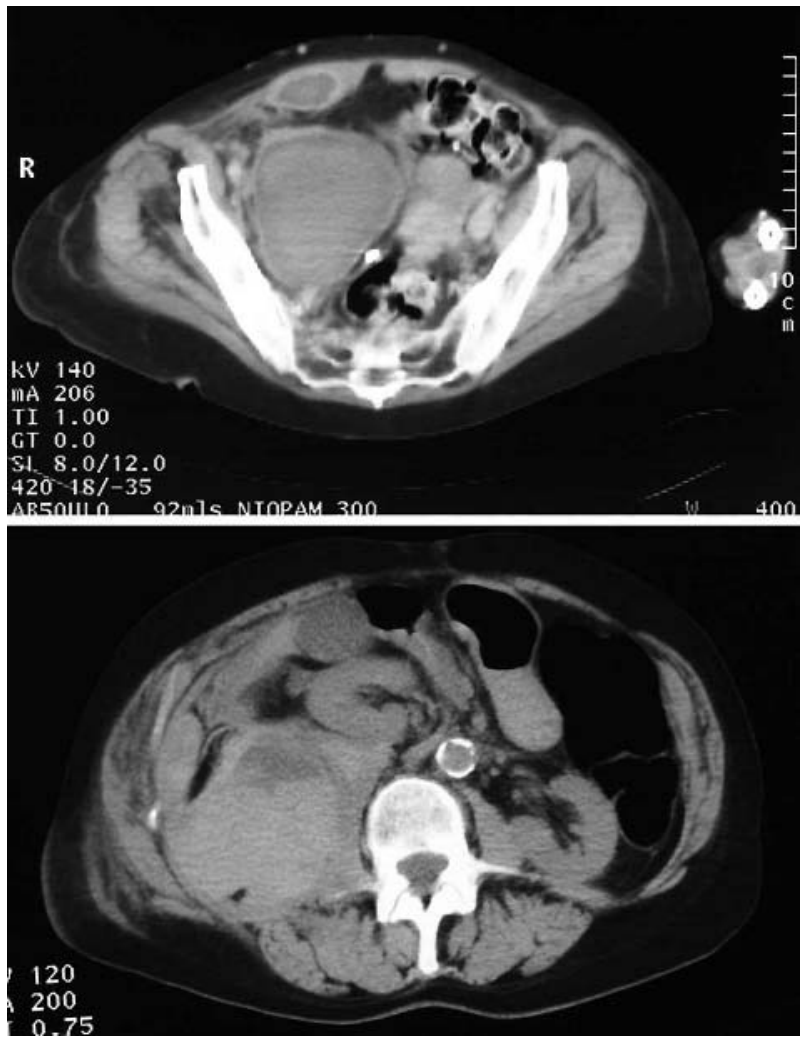

Figure 1 (A) Rectus sheath haematoma and a large retroperitoneal haematoma in patient 1 ; (B) large retroperitoneal haematoma in patient 2.

Various bleeding complications are commonly associated with warfarin, including gastrointestinal ${ }^{3}$ and intracranial bleeds, ${ }^{1}$ and rectus sheath ${ }^{4}$ and retroperitoneal haematomas. ${ }^{3-8}$ Conditions such as rectus sheath haematoma can be misdiagnosed as an acute abdomen and lead to unnecessary operations. ${ }^{4}$ Retroperitoneal haematoma has the potential to cause significant morbidity, principally due to compression of adjacent structures and blood loss, which can be fatal. ${ }^{3}$ Compression of the ureter can cause hydronephrosis and renal failure if bilateral. Compression of the IVC can cause deep vein thrombosis, which is particularly difficult to treat in a patient who has already suffered a bleeding complication from warfarin therapy. Femoral neuropathy is also described as a complication of iliacus haematoma. ${ }^{569}$

It has been reported that $1-7 \%$ of patients taking anticoagulants will suffer a bleeding complication each year. ${ }^{10}$ Such events are rare if the INR is $<3.0,{ }^{1}$ but not impossible. ${ }^{11}$ These cases highlight the importance of an awareness of the numerous drug interactions with warfarin, the results of which can be dramatic and potentially fatal. Close monitoring of INR is essential whenever any drug with the potential to interact is prescribed. Only in this way can the risk of bleeding complications for anticoagulated patients be minimised.

\section{Authors' affiliations}

S Phillips, A Barr, E Wilson, T A Rockall, J F Stebbing, Department of Surgery, Royal Surrey County Hospital, Egerton Road, Guildford, Surrey, UK

Competing interests: there are no competing interests

Correspondence to: Dr S Phillips, Department of Surgery, Royal Surrey County Hospital, Egerton Road, Guildford, Surrey GU2 7XX, UK; drsimonphillips@hotmail.com

Received 28 March 2004

Revised 12 May 2004

Accepted for publication 21 May 2004

\section{REFERENCES}

1 Hirsh J. Oral anticoagulant drugs. N Engl J Med 1991;324:1865-75.

2 Guidelines on oral anticoagulation: 3rd ed. Br J Haematol 1998;101:374-87.

3 Wilson RH, Mulholland C, Mackle EJ, et al. The need for closer control of warfarin therapy. J R Coll Surg Edinb 1994;39:171-3.

4 Stanton PE Jr, Wilson JP, Lamis PA, et al. Acute abdominal conditions induced by anticoagulant therapy. Am Surg 1974;40:1-14.

5 Jamjoom ZB, Al-Bakry A, Al-Momen A, et al. Bilateral femoral nerve compression by iliacus haematomas complicating anticoagulant therapy. Surg Today 1993;23:535-40.

6 Andrews FJ. Retroperitoneal haematoma after paracetamol increased anticoagulation. Emerg Med J 2002;19:84-5.

7 Marco M. Retroperitoneal haematoma and small bowel intramural haematoma caused by warfarin and miconazole interaction. Int J Oral Maxillofac Surg 1997; 27:485.

8 Morgan RJ, Bristol JB. Unusual findings in a patient taking warfarin. Postgrad Med J 1999;75:299-300

9 Lindner A, Zierz S. Retroperitoneal haemorrhage. N Engl J Med 2001;344:348.

10 Beyth RJ. Management of haemorrhagic complications associated with oral anticoagulant treatment. Expert Opin Drug Saf 2002;1:129-36.

11 Gonzalez C, Penado S, Llata L, et al. The clinical spectrum of retroperitoneal hematoma in anticoagulated patients. Medicine (Baltimore) 2003;82:257-62 